\title{
Control of first cleavage in single-cell reconstituted mouse embryos
}

\author{
L. C. Smith* $\ddagger$, I. Wilmut* and J. D. West $\dagger$ \\ *AFRC, Institute of Animal Physiology and Genetics Research, Edinburgh Research Station, \\ Roslin, Midlothian EH25 9PS, UK; and $\dagger$ Department of Obstetrics and Gynaecology, \\ Centre for Reproductive Biology, University of Edinburgh, Edinburgh EH3 9EH, UK
}

\begin{abstract}
Summary. Karyoplasts derived from mouse embryos at the initial and final stages of the first or second mitotic interphase were fused to early and late enucleated 1-cell embryos. The time of cleavage of reconstituted and control embryos was recorded at 1-h or 8-h intervals after manipulation. This enabled assessment of nuclear and cytoplasmic control over the mitotic apparatus of the 1-cell embryo. Early nuclei from 1- or 2-cell embryos fused to late enucleated embryos delayed cleavage but for only a few hours. However, late nuclei fused to early enucleated embryos were unable to advance the cytoplasmic timing of the next cleavage division. Furthermore, these reconstituted embryos stayed in interphase longer than did controls and many embryos with nuclei derived from late 2-cell embryos failed to cleave. These findings suggest that, allowing for a short period, early nuclei can synchronize with late cytoplasm with no major damage to the cleavage apparatus. It is proposed that this period is required for the completion of DNA synthesis by the early nuclei. However, late nuclei cannot induce mitosis before the expected cytoplasmic time, and, with 2-cell karyoplasts, this interaction causes many embryos to 'block' in interphase, without cleaving, suggesting incompatible nucleo-cytoplasmic interactions between late 2-cell karyoplast and early 1 -cell stage cytoplasm.
\end{abstract}

Keywords: embryo; nuclear transfer; cleavage; mouse

\section{Introduction}

Reconstitution of mammalian embryos using the technique of nuclear transplantation (McGrath \& Solter, 1983) has been widely used to investigate nucleo-cytoplasmic interactions during early development (reviewed by: McGrath \& Solter, 1986; Surani et al., 1987). Studies on the developmental potential of embryonic nuclei have shown that, while the exchange of pronuclei between zygotes has no deleterious influence on further viability, there is a substantial decrease in the ability of reconstituted embryos to develop in vitro to the blastocyst stage when pronuclei are replaced by a diploid nucleus derived from 2-cell or later stage blastomeres (McGrath \& Solter, 1984; Surani et al., 1986; Smith et al., 1988). It appears that this incompatibility is determined by the onset of transcriptional activity at the early stage of the second cell cycle (Braude et al., 1979; Flach et al., 1982). It is suggested that genomic activation would either render nuclei incapable of reactivating developmentally important genes and/or that stage-specific genes continue to be expressed after transfer and that their products affect further development of the reconstituted embryo (McGrath \& Solter, 1984; Surani et al., 1987; Solter, 1987). There is also evidence to suggest that some incompatibility is caused by cell-cycle-stage asynchronies between donor nucleus and recipient cytoplasm

†Present address: Centre de Recherche en Reproduction animale, Faculté de médecine vétérinaire, Université de Montreal, C.P. 5000, Saint-Hyacinthe, Québec, Canada J2S 7C6. 
since fewer embryos developed to blastocysts when pronuclei were exchanged between zygotes at different stages of the cell cycle (Smith et al., 1988).

Experiments with amphibian oocytes have indicated that the cytoplasm is dominant over the transplanted nucleus which assumes the activity characteristic of the host cell immediately after incorporation (Subtelny, 1965; Gurdon, 1968). Once activated, amphibian eggs proceed into a rapid, nearly synchronous series of several cell divisions during which period the embryos rely entirely on components stored in the cytoplasm (Newport \& Kirschner, 1984). Although enucleated activated eggs fail to divide, they undergo periodic surface contraction waves closely timed with the cell cycle (Sawai, 1979; Hara et al., 1980; Sakai \& Kubota, 1981) which further suggests that during early cleavage in these species the cytoplasmic cell-cycle oscillatory mechanism operates independently from the nucleus on which it acts.

In mice, the early morphological and molecular events that take place after fertilization have also been shown to be under a post-transcriptionally controlled programme, maternally inherited through the cytoplasm of the oocyte (reviewed by Johnson et al., 1984). Neither physical nor chemical enucleation influences any of the molecular changes that have been detected before the early 2-cell stage (Braude et al., 1979; Petzoldt et al., 1980; Flach et al., 1982; Bolton et al., 1984). At this stage, two bursts of transcriptional activity can be detected, immediately before and after DNA synthesis, which provide most messages for the following two cell cycles (Johnson \& Pratt, 1983; McLachlin et al., 1983). These findings suggest that the mouse embryo is controlled by maternally inherited cytoplasmic cell-cycle regulators up to the beginning of the 2-cell stage and that, after the activation of the embryonic genome, the nucleus starts providing the cell-cycle regulatory factors for the following stages of development. This suggestion is further supported by evidence for an autonomous cortical activity in anucleate mouse oocytes after artificial activation (Waksmundzka et al., 1984).

To analyse the cell cycle control mechanisms in reconstituted embryos, karyoplasts derived from 1- and 2-cell embryos at either the beginning or final stages of interphase were fused to enucleated 1-cell embryos at initial or final stages of the first cell cycle. The assessment of their time of cleavage from transplantation has enabled a better understanding of nucleo-cytoplasmic interactions in the control of first cleavage and on the relationship to the transcriptional activity of the donor nucleus.

\section{Materials and Methods}

Embryo source. Hybrid F1 females (C57BL/6 $\times \mathrm{CBA} / \mathrm{Ca}$ ), averaging 5-6 weeks of age, were superovulated by intraperitoneal injections of 5 i.u. PMSG and 5 i.u. hCG given $44-48 \mathrm{~h}$ apart. These injections were timed to provide embryos at early (E1: 20-22 h after hCG) or late (L1: 27-29 h after hCG) stages of the first cell cycle or at early (E2: $1-1.5 \mathrm{~h}$ after observed cleavage) or late (L2: $43-45 \mathrm{~h}$ after $\mathrm{hCG}$ ) stages of the second cell cycle. After hCG injection, females were paired with hybrid F1 males $(M F 1 \times$ SWR) and inspected the following morning for copulation plugs. Embryos were flushed from the oviducts at $\sim 1 \mathrm{~h}$ before microsurgery, using Hepes-buffered medium (M2: Quinn $e t$ al., 1982), and placed in bicarbonate-buffered Medium $16+0 \cdot 4 \%$ (w/v) BSA (M16 + BSA; Whittingham, 197l) until microsurgery.

Microsurgery. Embryos were placed in Medium M16 + BSA with cytoskeleton inhibitors $(1 \mu \mathrm{g}$ cytochalasin $\mathrm{D} / \mathrm{ml}$ : Sigma, Poole, Dorset, UK) and $0.3 \mu \mathrm{g}$ nocadazole $/ \mathrm{ml}$ (Sigma) for $30 \mathrm{~min}$ before being placed in Medium M2 with cytoskeletal inhibitors for another $30 \mathrm{~min}$ during microsurgery. Nuclear transplantations were carried out by the technique described by McGrath \& Solter (1983). Karyoplast and cytoplast transplantations were performed by removing a membrane-bound portion of cytoplasm (with or without nucleus) from the donor embryo and positioning it into the perivitelline space of the recipient enucleated embryo together with an inactivated viral suspension. Typically, fusion would occur within $1 \mathrm{~h}$ from manipulation.

Cleavage assessment. Micromanipulated and control embryos exposed to cytoskeletal inhibitors were washed in Medium M2, placed in Medium 16 + BSA drops under equilibrated paraffin oil and incubated at $37.5^{\circ} \mathrm{C}$ in an humidified atmosphere of $5 \% \mathrm{CO}_{2}$ in air immediately after completion of manipulation. At 8,16 and $24 \mathrm{~h}$ after manipulations, the embryos were removed from the incubator and placed on a dissecting microscope pre-heated stage at $37^{\circ} \mathrm{C}$ to assess the proportion which had cleaved at any particular time (cleavage rates). These periods for assessment were performed as quickly as possible to avoid large temperature fluctuations. In some experiments embryos 
were assessed at 1-h intervals for periods lasting between 8 and $10 \mathrm{~h}$. Every experiment had controls of two kinds. One was composed of embryos that experienced periods of exposure to manipulation medium exactly as treated embryos (manipulated control) and another which was placed in culture immediately after their removal from mouse oviducts (non-manipulated control). Cleavage rates for treated and control groups were compared using Fisher's exact test for two-way contingency tables.

\section{Results}

An indication of the relationship between the developmental stages at which embryos were manipulated for karyoplast and cytoplast transplantations and the known molecular and cellular events in the first and second cell cycle are shown in Fig. 1. Cleavage rates for manipulated and non-manipulated controls were recorded and found to be similar at all periods analysed after manipulation (L. C. Smith, unpublished observation), indicating that the exposure of embryos to the manipulation medium had no effect on the timing of cleavage. Therefore, further analysis was based on comparisons to control embryos exposed to the manipulation procedure (manipulated controls).

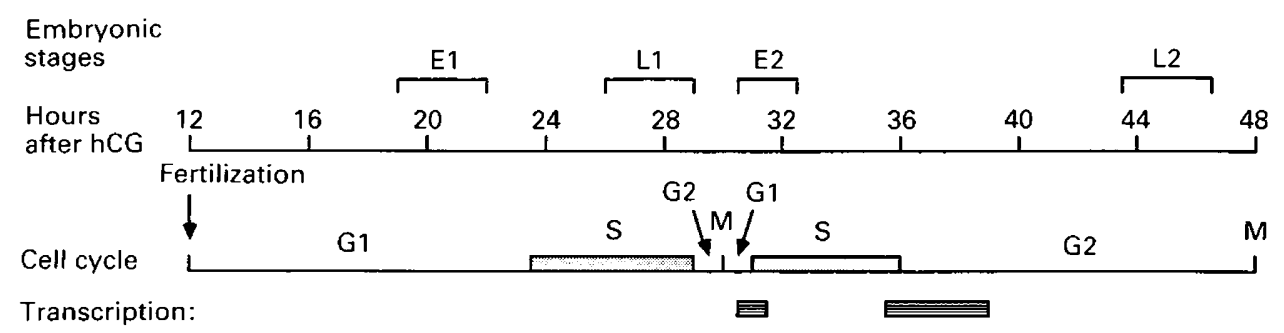

Fig. 1. Molecular and cellular events during first and second cell cycles of mouse embryos and their relationship to the time in which 1- and 2-cell embryos were manipulated (adapted from Bolton et al., 1984; Howlett \& Bolton, 1985).

\section{Transfers within the cell cycle}

No significant difference was found, at any period after manipulation, between the cleavage rates of control and reconstituted embryos derived from transfers between similar stages of interphase $(P>0.05)$ (Table 1). This indicates that the technique of nuclear transplantation had no effect on the time of cleavage of embryos in the reconstituted groups.

Table 1. Cleavage proportions per unit time of control and reconstituted embryos derived from the transplantation of pronuclear karyoplasts between early (E1; 20-22 h after hCG) and late (L1; 27-29 h after hCG)

1-cell embryos assessed at 8 -h intervals from manipulations

\begin{tabular}{ccccccc}
\hline & \multicolumn{2}{c}{} & & & \multicolumn{2}{c}{$\begin{array}{c}\text { Cleavage proportions (\%) } \\
\text { after manipulation }\end{array}$} \\
\cline { 2 - 3 } \cline { 6 - 7 } Group & Nucleus & Cytoplasm & $\begin{array}{c}\text { No. of } \\
\text { embryos }\end{array}$ & $8 \mathrm{~h}$ & $16 \mathrm{~h}$ & $24 \mathrm{~h}$ \\
\hline 1 & Control & El & 84 & $4 \cdot 8$ & 100 & 100 \\
2 & El & El & 45 & $2 \cdot 2$ & 100 & 100 \\
3 & L1 & El & 34 & $2 \cdot 9$ & $82 \cdot 4^{*}$ & $97 \cdot 1$ \\
4 & Control & Ll & 43 & $88 \cdot 4$ & 100 & 100 \\
5 & L1 & Ll & 41 & 97.6 & 100 & 100 \\
6 & E1 & Ll & 35 & 22.9 & 100 & 100 \\
\hline
\end{tabular}

*'Asynchronous' group differs significantly from the respective 'synchronous' group $(P<0.01)$. 
Embryos derived from fusions between karyoplasts and enucleated embryos at opposite extremes of interphase showed significant changes in cleavage time after manipulation when compared to the controls with the same type of cytoplasm (Table 1). El karyoplasts fused to Ll cytoplasts (Group 6) had significantly higher rates of cleavage at $8 \mathrm{~h}$ after manipulation when compared to the E1 controls (Group 1) $(P<0.01)$ and significantly lower cleavage rates when compared to the $\mathrm{Ll}$ controls (Group 4$)$ at the same period after manipulation $(P<0 \cdot 01)$. There were no differences at any further period after manipulation $(P>0.05)$. These results show that the length of the interphase stage of the reconstituted embryo was intermediate between the controls for the donor karyoplast nucleus and recipient cytoplasm.

Although there were no significant differences at $8 \mathrm{~h}$ after manipulation $(P>0.05)$, reconstituted embryos derived from the fusion of L1 karyoplasts to E1 cytoplasts (Group 3) had a significantly lower cleavage rate at $16 \mathrm{~h}$ after manipulation when compared to the 'synchronous' Group 2 embryos $(P<0.01)$. Part of this effect was caused by a small proportion of reconstituted embryos $(2.9 \%)$ that had not cleaved by $24 \mathrm{~h}$ after manipulation and did not cleave at any time thereafter. However, the cleavage rate at $16 \mathrm{~h}$ after manipulation relative to the embryos that did eventually cleave $(84 \cdot 8 \%)$ was also significantly lower for the 'asynchronous' than for 'synchronous' reconstituted embryos and controls $(100 \%)(P<0.05)$. These results indicate that the late karyoplast was not only unable to shorten the interphase of the reconstituted embryo, but that the interaction between nucleus and cytoplasm caused an extension beyond the expected cleavage time for the recipient E1 controls.

\section{Transfers across the cell cycle}

The effects on time of cleavage of transfers between embryos from different cell cycles were tested by fusing early (E2) and late (L2) 2-cell karyoplasts to enucleated 1-cell embryos (Table 2). Reconstituted embryos derived from L2 karyoplasts (Group 10) did not have cleavage rates significantly different from those of L1 (Group 9) or L2 (Group 11) controls at any time after manipulation $(P>0 \cdot 05)$. However, when E2 karyoplasts were fused to $\mathrm{L} 1$ enucleated embryos (Group 8), significantly fewer embryos had cleaved at $8 \mathrm{~h}$ after manipulation as compared to $\mathrm{Ll}$ controls (Group 9) $(P<0.01)$. Although a small proportion $(2 / 37=5.4 \%)$ of reconstituted embryos did not cleave at all after reconstitution, the cleavage rate at 16 and $24 \mathrm{~h}$ after manipulation of the remaining group was still similar to that of the controls $(P>0.05)$. However, these embryos (Group 8) had significantly higher cleavage rates when compared to the E2 donor karyoplast control (Group 7) at 8,16 and $24 \mathrm{~h}$ after manipulation $(P<0.01)$. These results indicate an effect of the E2 karyoplast in extending the interphase of the reconstituted embryo beyond the expected time of cleavage of the $\mathrm{L} 1$ recipient cytoplasm control. However, this extension was substantially smaller than the expected donor karyoplast cleavage time, since E2 controls only cleaved approximately $12 \mathrm{~h}$ later. A similar effect was shown when recording the cleavage rates at hourly intervals after manipulation (Fig. 2). In this experiment, the interphase of the E2 reconstituted group was $46 \mathrm{~h}$ longer than that recorded for the $\mathrm{L} 2$ reconstituted and control group.

Cleavage rates for reconstituted embryos derived from the fusion of 2-cell karyoplasts to E1 enucleated embryos are presented in Table 3. There was no significant difference between the times of cleavage of embryos derived from fusions using E2 karyoplast (Group 13) and the E1 controls (Group 14) at any period after manipulation $(P>0.05)$. However, the cleavage rate of these reconstituted embryos differed significantly from that of the E2 controls (Group 12) at 16 and $24 \mathrm{~h}$ after manipulation $(P<0.01)$, which indicates that the karyoplast was unable to extend interphase beyond the expected cleavage time for the $\mathrm{E} 1$ recipient cytoplasm. This interpretation was confirmed by a further experiment in which observations were performed at 1 -h intervals after manipulation (Fig. 3). 
Table 2. Cleavage proportions per unit time of control and reconstituted embryos derived from the transplantation of karyoplast of early (E2; $1-1.5 \mathrm{~h}$ after observed cleavage) and late (L2; $43-45 \mathrm{~h}$ after hCG) 2-cell embryos to enucleated late ( $\mathrm{Ll} ; 27-29 \mathrm{~h}$ after hCG) 1-cell embryos

\begin{tabular}{|c|c|c|c|c|c|c|}
\hline \multirow[b]{2}{*}{ Group } & \multicolumn{2}{|c|}{ Stages of: } & \multirow{2}{*}{$\begin{array}{l}\text { No. of } \\
\text { embryos }\end{array}$} & \multicolumn{3}{|c|}{$\begin{array}{l}\text { Cleavage proportions (\%) } \\
\text { after manipulation }\end{array}$} \\
\hline & Nucleus & Cytoplasm & & $8 \mathrm{~h}$ & $16 \mathrm{~h}$ & $24 \mathrm{~h}$ \\
\hline 7 & E2 & Control & 25 & None & None & $32 \cdot 0$ \\
\hline 8 & E2 & $\mathrm{Ll}$ & 37 & $24 \cdot 3^{* *}$ & $94 \cdot 6^{*}$ & 94.6 \\
\hline 9 & Control & Ll & 100 & $73 \cdot 0$ & 100 & 100 \\
\hline 10 & L2 & Ll & 40 & $75 \cdot 0$ & 100 & 100 \\
\hline 11 & L2 & Control & 44 & 65.9 & 100 & 100 \\
\hline
\end{tabular}

*Differs significantly from $\mathrm{E} 2$ controls $(P<0.01)$.

**Differs significantly from L2 controls and $\mathrm{E} 2$ controls $(P<0.01)$.

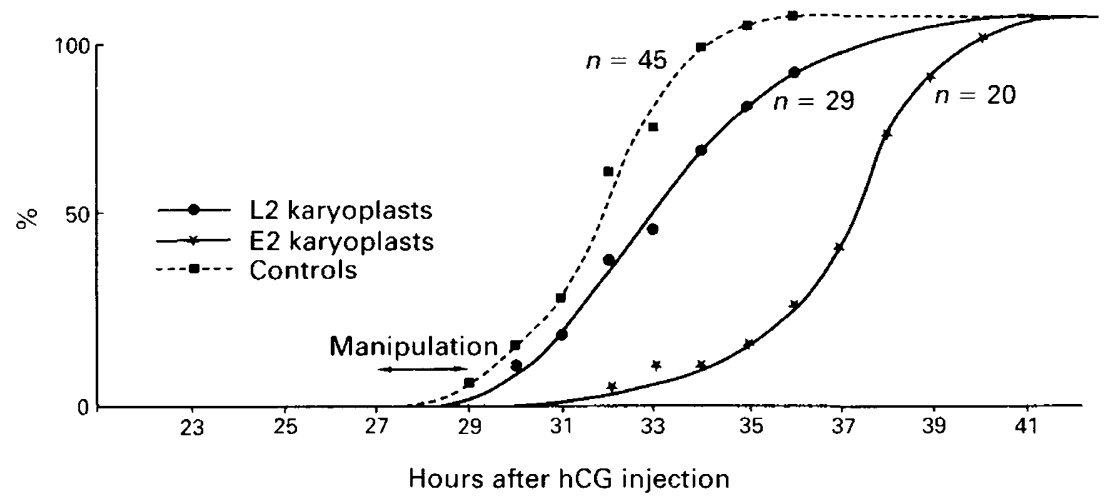

Fig. 2. Cleavage proportions per unit time of reconstituted embryos derived from the transplantation of karyoplasts of early (E2) and late (L2) 2-cell embryos fused to late 1-cell (L1) enucleated embryos assessed at 1 -h intervals immediately after manipulation.

Table 3. Cleavage proportions per unit time of control and reconstituted embryos derived from karyoplast transplantations between early (E2; $1-1 \cdot 5 \mathrm{~h}$ after observed cleavage) and late (L2; 43-45 h after hCG) 2-cell embryos to enucleated early l-cell (El 22-28 h after hCG) embryos assessed at 8-h intervals from manipulations

\begin{tabular}{|c|c|c|c|c|c|c|}
\hline \multirow[b]{2}{*}{ Group } & \multicolumn{2}{|c|}{ Stages of: } & \multirow{2}{*}{$\begin{array}{l}\text { No. of } \\
\text { embryos }\end{array}$} & \multicolumn{3}{|c|}{$\begin{array}{l}\text { Cleavage proportions }(\%) \\
\text { after manipulation }\end{array}$} \\
\hline & Nucleus & Cytoplasm & & $8 \mathrm{~h}$ & $16 \mathrm{~h}$ & $24 \mathrm{~h}$ \\
\hline 12 & E2 & Control & 40 & None & None & 35.0 \\
\hline 13 & E2 & E1 & 39 & None & $100^{* *}$ & $100^{*}$ \\
\hline 14 & Control & E1 & 52 & 2.0 & 100 & 100 \\
\hline 15 & L2 & El & 40 & None & $27 \cdot 5^{*}$ & $45 \cdot 0^{*}$ \\
\hline 16 & L2 & Control & 34 & $67 \cdot 6$ & 100 & 100 \\
\hline
\end{tabular}

*Differs significantly from El controls $(P<0 \cdot 01)$.

**Differs significantly from $\mathrm{E} 2$ controls $(P<0.01)$. 


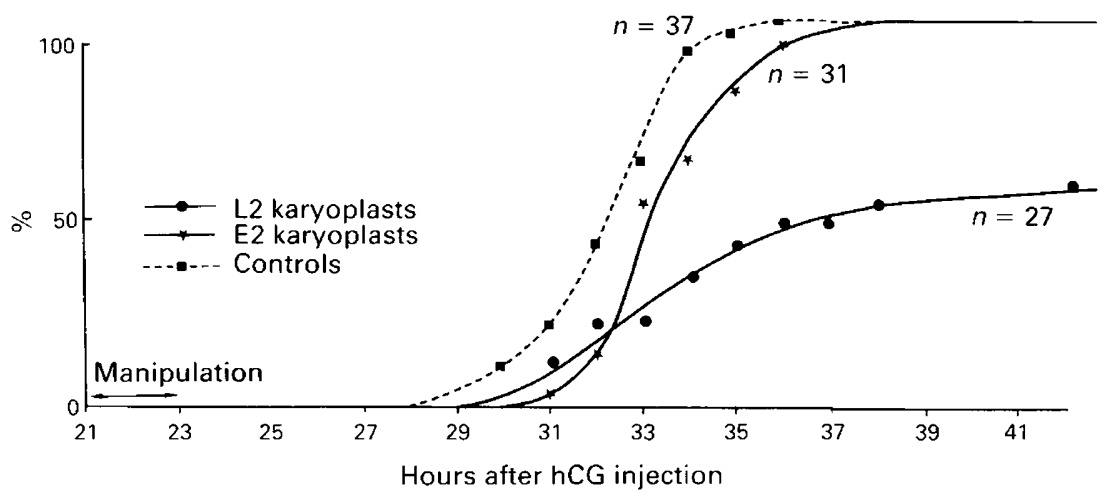

Fig. 3. Cleavage proportions per unit time of reconstituted embryos derived from the transplantation of karyoplasts of early (E2) and late (L2) 2-cell embryos fused to early 1-cell (E1) enucleated embryos assessed at 1 -h intervals beginning $6 \mathrm{~h}$ after manipulation.

Reconstituted embryos derived from the fusion of L2 karyoplasts to E1 enucleated embryos (Group 15) had not cleaved by $8 \mathrm{~h}$ after manipulation, producing a cleavage rate similar to that of the recipient cytoplasm E1 controls $(P>0.05)$ but significantly different from the L2 donor karyoplast controls (Group 16) of which more than two-thirds had already cleaved $(P<0.01)$. These results show that the L2 karyoplast had no influence in shortening the interphase of the reconstituted embryos when compared to the El controls. Moreover, the cleavage rate of the reconstituted embryos at 16 and $24 \mathrm{~h}$ after manipulations was significantly lower than that of the El cytoplasm controls $(P<0.01)$. Most of this effect seems to have been caused by a large proportion $(55 \%)$ of the reconstituted embryos not cleaving at any time after manipulation. Of those embryos that did eventually cleave, $61 \%(11 / 18)$ had cleaved by $16 \mathrm{~h}$ after manipulation $(61 \%)$, still significantly lower proportion than the E1 control group that had all cleaved by then $(P<0.01)$. Similar results were observed at hourly cleavage assessments of reconstituted embryos (Fig. 3), which further indicates that the L2 karyoplast was not only unable to bring about an earlier cleavage, but that it either lengthened the interphase or completely blocked cleavage of the reconstituted embryos.

\section{Cytoplast transplantations}

Fusion of small cytoplasts from karyoplast donor embryos to control embryos was performed to test whether the effects of the karyoplasts on cleavage were due to the nucleus alone or to the small amount of cytoplasm and plasma membrane which is added to the reconstituted embryo at

Table 4. Cleavage proportions per unit time of control and reconstituted embryos derived from the transplantation of cytoplasts from 1- and 2-cell early (E1, E2) and late (L1, L2) embryos to early (E1) and late (L1) 1-cell embryos

\begin{tabular}{cccccccc}
\hline & \multicolumn{2}{c}{} & & \multicolumn{3}{c}{$\begin{array}{c}\text { Cleavage proportions (\%) } \\
\text { after manipulation }\end{array}$} \\
\cline { 2 - 3 } \cline { 6 - 8 } Group & Cytoplast & Embryo & \multirow{2}{c}{$\begin{array}{c}\text { No. of } \\
\text { embryos }\end{array}$} & $8 \mathrm{~h}$ & $16 \mathrm{~h}$ & $24 \mathrm{~h}$ \\
\hline 17 & Control & E1 & 104 & $1 \cdot 0$ & 100 & 100 \\
18 & L1 & E1 & 36 & $2 \cdot 8$ & 100 & 100 \\
19 & L2 & E1 & 37 & $2 \cdot 7$ & 100 & 100 \\
20 & E1 & L1 & 28 & 100 & 100 & 100 \\
21 & E2 & L1 & 24 & $91 \cdot 7$ & 100 & 100 \\
22 & Control & L1 & 43 & 88.4 & 100 & 100 \\
\hline
\end{tabular}


the time of karyoplast fusion. Cleavage rates of the cytoplast-transplanted embryos are presented in Table 4. The fusion of either L1 (Group 18) or L2 (Group 19) cytoplasts to E1 embryos caused no significant effect on their cleavage rate when compared to the E1 controls (Group 17) at 8, 16 or $24 \mathrm{~h}$ after manipulation $(P>0 \cdot 05)$. Similarly, there was no significant effect on cleavage time after fusing cytoplasts derived from E1 (Group 20) and E2 (Group 21) embryos to L1 embryos when comparing these to the $\mathrm{L} 1$ controls (Group 22) at 8, 16 and $24 \mathrm{~h}$ after manipulation $(P>0.05)$. These results show that the cytoplasm and plasma membrane of donor karyoplasts had no effect on the cleavage rates of the reconstituted embryos, indicating that the effects observed earlier were caused by the interaction between the donor nucleus (alone) and the cytoplasm of the recipient enucleated embryo.

\section{Discussion}

These findings indicate that the cell-cycle regulatory apparatus operating during the first cell cycle of mouse embryos can be altered by replacing the pronuclei by embryonic karyoplasts at different stages of interphase. Furthermore, these alterations in the timing of cleavage were caused by the donor nucleus alone since cytoplast transfers did not interfere with the cell cycle timing. This suggests that, although transcription is not required until the second cleavage, nucleus and cytoplasm do interact for the control of the first mitotic cleavage.

Nuclei at early stages of interphase were able to extend the interphase stage of recipient cytoplasm close to first cleavage. This effect was observed with early stage nuclei from the first (E1) and second (E2) cell cycles and appeared to be similar for the two nuclei sources (approximately 4-6 h). It is unlikely that factors such as cell-cycle lengths and transcriptional activity of the donor nuclei were responsible for this effect since these vary considerably between the 1-and 2-cell stages (Bolton et al., 1984; Howlett \& Bolton, 1985). However, the S phase (DNA synthesis) of cleavagestage embryos is similar and lasts for about 4-7 h (Smith \& Johnson, 1986). This period is close to the length of time taken by the L1 enucleated embryos fused to E2 nuclei to cleave (Fig. 2), which may indicate that the completion of DNA replication was required before these embryos could proceed into cleavage. This suggestion is supported by previous findings using somatic cell hybrids for which it was shown that, when G2 and mitotic somatic cells are fused to G1- and S-phase cells, the entry of these hybrid cells into mitosis is delayed until the G1- or S-phase nuclei have completed DNA synthesis, and, subsequently, both nuclei have entered mitosis synchronously (Rao \& Johnson, 1970; Rao et al., 1975).

Late-stage nuclei from the first (L1) or second (L2) cell cycle were unable to bring about an earlier cleavage when fused to the cytoplasm of an enucleated early stage 1-cell embryo (E1). The fact that the transcriptionally active 2-cell nucleus was equally as incapable of shortening the cell cycle as the transcriptionally inactive late stage pronuclei gives further support to a cleavage control mechanism operating at a post-transcriptional level. Adlakha et al. (1983) have described a mitotic inhibitory factor in somatic cell extracts which peaks during G1 and S-phase. As the recipient El cytoplasm was at the same stage of the cell cycle, it is possible that these same factors could be present in the early embryo and, therefore, have caused the mitotic arrest. However, the L2 nucleus was substantially more able to cause a complete arrest of the reconstituted embryos when compared to their $\mathrm{L} 1$ counterparts. This indicates that the incompatibility may be related to the release of factors specific to the 2-cell stage and, therefore, in some way attached to the transcriptional activity of the donor nucleus. Morphological abnormalities of the genome such as 'pulverization' and chromatid breakage have been shown to occur when 8-cell nuclei are fused to fertilized and parthenogenetically activated embryos (Dyban et al., 1988).

Previous experiments have shown that reconstituted embryos derived from fusions between early or late 2-cell nuclei and late 1-cell cytoplasm are capable of developing to blastocysts in vitro at similar and reasonably high $(60 \%)$ proportions (Smith et al., 1988). Firstly, this indicates that the accomplishment of synchrony between the early 2-cell nucleus and late cytoplasm (which probably 
occurs during the 4-h interphase extension period) results in little harm for further development. Secondly, the similarity between the proportions of early and late 2-cell nuclei in supporting blastocyst formation suggests that stage-specific factors are either not present or are unable to affect their development. However, when 2-cell nuclei were fused to early cytoplasm a larger proportion of the reconstituted embryos did not develop into blastocysts in vitro. In this case, the prolonged period between manipulation and cleavage may allow the early 2-cell nucleus to release stage-specific factors which, although unable to affect cleavage, seem to be toxic for further stages during preimplantation development. Contrary to the effect shown by the early nucleus, the late 2-cell nucleus seems to have lost the ability to reset the oscillatory cell-cycle apparatus with that of the cytoplasm, causing a cleavage block. None the less, a substantial proportion of those reconstituted embryos that do in due course cleave should eventually develop into normal blastocysts. This less harmful long-term effect may be indicative of the fact late 2-cell nuclei have already ended their transcriptional activity at the time of karyoplast removal (Bolton et al., 1984). Further biochemical and cytological studies are required to characterize the mitotic controlling factors in mouse embryos and the activity of nuclear transplanted embryos. These would provide a better understanding of the cell-cycle control mechanism operating during early embryonic development in mammals, and may also improve the efficiency of nuclear transplantations at these early stages.

We thank Dr R. H. F. Hunter for reading and commenting on the manuscript preparation and Miss Silvie Legace for secretarial assistance. L.C.S. was a recipient of a grant from CNPq-FAPESP, Brazil.

\section{References}

Adlakha, R.C., Sahasrabuddhe, C.G., Wright, D.A. \& Rao, P.N. (1983) Evidence for the presence of inhibitors of mitotic factors during Gl period in mammalian cells. J. Cell Biol. 97, 1707-1713.

Bolton, V.N., Oades, P.J. \& Johnson, M.H. (1984) The relationship between cleavage, DNA replication and gene expression in the mouse 2-cell embryo. $J$. Embryol. exp. Morph. 79, 139-163.

Braude, P.R., Pelham, H., Flach, G. \& Lobatto, R. (1979) Post-translational control in the early mouse embryo. Nature, Lond. 282, 102-105.

Dyban, A.P., Lee, K., O’Neill, G.T., Speir, S. \& Kaufman, M.H. (1988) Cytogenetic study of silverstaining NOR in 8-cell-stage mouse blastomeres fused to 1-cell-stage embryos. Development 104, $453-463$.

Flach, G., Johnson, M.H., Braude, P.R., Taylor, R.A.S. \& Bolton, V.N. (1982) The transition from maternal to embryonic control in the 2-cell mouse embryo. EMBO Jl 1, 681-686.

Gurdon, J.B. (1968) Changes in somatic cell nuclei inserted into growing and maturing amphibian oocytes. J. Embryol. exp. Morph. 20, 401-414.

Hara, K., Tydeman, P. \& Kirschner, M.W. (1980) A cytoplasmic clock with the same period as the division cycle in Xenopus eggs. Proc. natn. Acad. Sci. USA 77, 462-466.

Howlett, S.K. \& Bolton, V.N. (1985) Sequence and regulation of morphological and molecular events during the first cell cycle of mouse embryogenesis. $J$. Embryol. exp. Morph. 87, 175-206.

Johnson, M.H. \& Pratt, H.P.M. (1983) Cytoplasmic localizations and cell interactions in the formation of the mouse blastocyst. In Time, Space and Pattern in
Embryonic Development, pp. 287-312. Eds W. R. Jeffrey \& R. A. Raff. Alan R. Liss Inc., New York.

Johnson, M.H., McConnell, J. \& Van Blerkom, J. (1984) Programmed development in the mouse embryo. $J$. Embryol. exp. Morph. 83 (Suppl.), 197-231.

McGrath, J. \& Solter, D. (1983) Nuclear transplantation in mouse embryos. J. exp. Zool. 288, 355-362.

McGrath, J. \& Solter, D. (1984) Inability of mouse blastomere nuclei transferred to enucleated zygotes to support development in vitro. Science, $N Y \mathbf{2 2 6}$, $1317-1319$.

McGrath, J. \& Solter, D. (1986) Nucleo-cytoplasmic interactions in the mouse embryo. J. Embryol. exp. Morph. 97 (Suppl.), 277-289.

McLachlin, J.R., Cavaney, S. \& Kidder, G.M. (1983) Control of gap junction formation in early mouse embryos. Devl Biol. 98, 155-164.

Newport, J. \& Kirschner, M. (1984) Regulation of cell cycle during early Xenopus development. Cell 37, $73 \mathrm{I}-742$.

Petzoldt, U., Hoppe, P.C. \& Illmensee, K. (1980) Protein synthesis in enucleated fertilized and unfertilized mouse eggs. Wilhelm Roux' Arch. Devel. Biol. 189, 215-219.

Quinn, P., Barros, C. \& Whittingham, D.G. (1982) Preservation of hamster oocytes to assay the fertilizing capacity of human spermatozoa. $J$. Reprod. Fert. 66, 161-168.

Rao, P.N. \& Johnson, R.T. (1970) Mammalian cell fusion: studies on the regulation of DNA synthesis and mitosis. Nature, Lond. 225, 159-164.

Rao, P.N., Hittleman, W.N. \& Wilson, B.A. (1975) Mammalian cell fusion: VI, Regulation of mitosis in binucleate HeLa cells. Exp/ Cell Res. 90, 40-46. 
Sakai, M. \& Kubota, H. (1981) Cyclic surface changes in nonucleate egg fragments of Xenopus laevis. Devel. Growth Differ. 23, 41-49.

Sawai, T. (1979) Cyclic changes in the cortical layer of non-nucleated fragments of the newt's egg. $J$. Embryol. exp. Morph. 51, 183-193.

Smith, L.C., Wilmut, I. \& Hunter, R.H.F. (1988) Influence of cell cycle stage at nuclear transplantation on the development in vitro of mouse embryos. $J$. Reprod. Fert. 84, 619-624.

Smith, R.K.W. \& Johnson, M.H. (1986) Analysis of the third and fourth cell cycles of the mouse early development. J. Reprod. Fert. 76, 393-399.

Solter, D. (1987) Genetic manipulation in mammalian development. In Molecular Genetics in Developmental Neurobiology, pp. 91-100. Ed. Y. Tsukada. Japan Sci. Socs Press, Osaka.

Subtelny, S. (1965) On the nature of the restricted differentiation-promoting ability of transplanted Rana pipiens nuclei from differentiating endoderm cells. $J$. exp. Zool. 159, 59-92.

Surani, M.A.H., Barton, S.C. \& Norris, M.L. (1986) Nuclear transplantation in the mouse: heritable differences between parental genomes after activation of the embryonic genome. Cell 45, 127-136.

Surani, M.A.H., Barton, S.C. \& Norris, M.L. (1987) Experimental reconstruction of mouse eggs and embryos: an analysis of mammalian development. Biol. Reprod. 36, 1-16.

Waksmundzka, M., Krisiak, E., Karasiewicz, J., Czolowska, R. \& Tarkowski, A.K. (1984) Autonomous cortical activity in mouse eggs controlled by a cytoplasmic clock. J. Embryol. exp. Morphol. 79, 77-96.

Whittingham, D.G. (1971) Culture of mouse ova. $J$. Reprod. Fert., Suppl. 14, 7-12.

Received 17 August 1989 